\title{
Abdominal Aortic Aneurysmatic Sac Shrinking is the New Paradigm after Endovascular Treatment
}

\author{
Gaudencio Espinosa ${ }^{1}$, Pedro Saad ${ }^{1 *}$, Giovanni di Luccio ${ }^{1}$, Pedro Duarte Vaz ${ }^{1}$, Luiz Baptista ${ }^{1}$ \\ and Carlos Magliano ${ }^{2}$ \\ ${ }^{1}$ Department of Surgery, Universidade Federal do Rio de Janeiro, Brazil \\ ${ }^{2}$ Department of Surgery, Instituto Nacional de Cardiologia, Brazil
}

\begin{abstract}
Objectives: Aneurysmal Sac (SAC) absorption after endovascular treatment (EVAR) of Abdominal Aortic Aneurysms (AAA) is related to a better prognosis but its long-term mandatory and predictive factors remain unclear. Our study aims to assess the impact of its total resorption on patient survival, as well as the factors that favor resorption.
\end{abstract}

Methods: We followed a187 patients who underwent EVAR with a fully thrombosed SAC for 22 years in the postoperative control of Angio-CT. We established the significance of the factors for SAC resorption by logistic regression models, evaluating comorbidities, diameter, sex and age of the patient. We also compared the impact of absorption sac absorption with survival.

Results: Diameter and age were significant for the resorption of the SAC together or even independently ( $\mathrm{p}$-value $<0.001)$, the diameter (OR-0.29) showed a greater influence than age (OR= -0.063). The comorbidities studied and the sex of the patients was not statistically significant. Patients who had significant absorption $(\geq 10 \mathrm{~mm}$ ) had a survival rate of $12.72 \pm 0.96$ years, those with moderate absorption ( $5 \mathrm{~mm}$ to $9 \mathrm{~mm}$ ) had of $8.34 \pm 1.62$ years and those without significant resorption or growth had $3.27 \pm 0.48$ years ( $\mathrm{p}$-value $<0.001$ ). Among patients with absorption of $\geq 5$ $\mathrm{mm}$ in the first year, we found greater chances of total absorption $(\mathrm{OR}=4.72 \mathrm{p}$-value $<0.001)$.

Conclusion: Total sac resorption proved to be an important prognostic factor for patient survival after EVAR. The age of the patient and mainly the initial diameter of the sac were the factors significantly associated with the resorption of the sac.

\section{OPEN ACCESS}

*Correspondence:

Pedro Saad, Department of Surgery, Universidade Federal do Rio de Janeiro, Tel: 5521999829636;

E-mail: pedromsaad@gmail.com

Received Date: 17 Jun 2021

Accepted Date: 28 Jun 2021

Published Date: 05 Jul 2021

Citation:

Espinosa G, Saad P, di Luccio G, Duarte Vaz $P$, Baptista L, Magliano C. Abdominal Aortic Aneurysmatic Sac Shrinking is the New Paradigm after Endovascular Treatment. Clin Surg.

2021; 6: 3237

Copyright $\odot 2021$ Pedro Saad. This is an open access article distributed under the Creative Commons Attribution License, which permits unrestricted use, distribution, and reproduction in any medium, provided the original work is properly cited.
Keywords: Endovascular treatment; Long-term follow up; Sac shrinkage; Aneurysm resorption

\section{Introduction}

The aorta is the largest artery in the body and the most frequently affected by degenerative aneurysms, of which over $80 \%$ occur in its infrarenal portion. The main complication of an aneurysm is rupture, which has a mortality rate of around $90 \%$. It is estimated that the prevalence of abdominal aortic aneurysms is $2 \%$ in the population aged 60 and approximately $5 \%$ after 70 . It is 2 to 3 times more common in males [1]. Endovascular Aneurysm Repair (EVAR) is an alternative to traditional open surgery and is considered the main option for selected patients [2]. Although EVAR offers immediate advantages over open surgical repair such as a lower mortality rate, lifelong surveillance is required due to the risk of complications such as endoleaks, graft migration and aneurysmal sac enlargement [3]. During the surveillance, the aneurysmal sac shrinkage is considered a marker for clinical success, signalizing the exclusion of the aneurysm from arterial pressure. It is also related to a lower mortality rate [4]. Despite the importance of this outcome, there is no consensus on the determining factors for the evolution of the aneurysmal sac after EVAR [5]. The objective of this study was to identify the factors that expedite the sac remodeling post-EVAR.

\section{Methods}

The protocol for this study was approved by the ethics and research committee of the Hospital Universitário Clementino Fraga Filho, with registration number 17412. All subjects gave their informed consent. From 1997 to 2008, patients undergoing EVAR of an infrarenal AAA in a public hospital in Rio de Janeiro, Brazil, were enrolled in this protocol. 363 patients received modular bifurcated devices, 14 aortouniliac devices and 2 patients received straight stent-grafts. All procedures were carried out by the same surgical team, using exclusively the talent endovascular stent-graft 


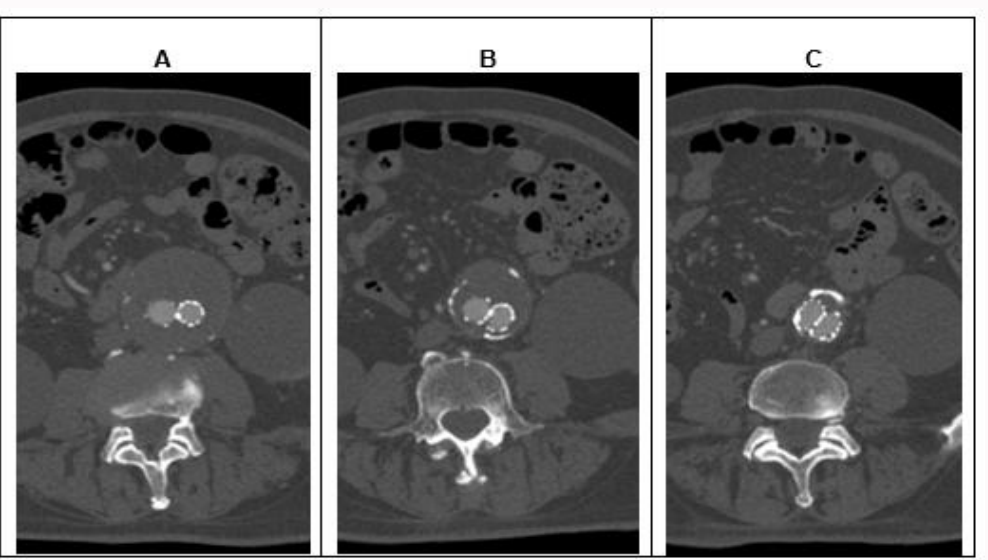

Figure 1: Images of an aneurysmal sac 30 days (A), 2 years (B) and 5 years (C) after EVAR demonstrating the total absorption of the aneurysmal sac.

(Medtronic AVE, Santa Rosa, California). We considered candidates for endovascular treatment were patients with AAA with: (1) SAC diameter $\geq 45 \mathrm{~mm}$; (2) patients with a diameter equal to or greater than twice the diameter of the normal infrarenal aorta; (3) patients with a greater than $5 \mathrm{~mm}$ increase in AAA diameter in six months. Patients were excluded from the study: (1) from another geographic region that could not be followed $(n=103)$; (2) patients with nonbifurcated stents ( $\mathrm{n}=22)$; (3) Patients undergoing the procedure with clinical signs of rupture or hemodynamic instability $(n=5)$; (4) Patients with inflammatory aneurysm $(n=2)[6]$. In the present analysis, only patients with complete sac thrombosis and with available annual postoperative follow-up CT angiography were included. Out of a total of 231 patients, in order to have a group of patients as homogeneous as possible in long-term follow-up, the group of patients that showed thrombosis in the 30-day postoperative control computed tomography scan was chosen. Complete sac. Patients who had some type of endoleak $(n=44)$ were excluded. In the present analysis, only patients with complete aneurysmal sac thrombosis and with available preoperative and annually postoperative follow-up angiotomography scans were included (Figure 1).

\section{Statistical Analysis}

Categorical variables are given as a count and percentage of patients and compared using $\chi^{2}$ or Fisher's exact test. Continuous variables were summarized using the mean and its standard error and analyzed with 2-tailed t-tests or compared with a Mann-Whitney $\mathrm{U}$-test for independent data as appropriate. Associations between clinical characteristics (age, gender, smoking, hypertension, diabetes, Chronic Obstructive Pulmonary Disease (COPD) and aneurysm size) and the occurrence of complete aneurysmal sac shrinkage were tested using logistic regression models. The shrinkage was considered complete when the aneurysmal sac touched the prostheses (Figure 1 ). The variables with significant associations on univariate analysis (P-value $<0.2$ ) were selected by the stepwise method and they were subsequently tested on a multivariate logistic regression analysis. Model comparisons were conducted using the Akaike Information Criterion (AIC) together with P-values based on likelihood ratio testing. Lower values of AIC represent a more parsimonious fit of the model to the data set and provide a measure of how well the model represents the patient data on which it is based. $\mathrm{P}<0.05$ was considered statistically significant. All data was analyzed using the $\mathrm{R}$ software ( $\mathrm{R}$ Core Team-2017 A language and environment for statistical computing. R Foundation for Statistical Computing,
Vienna, Austria).

\section{Results}

A total of 187 patients fulfilled the selection criteria and they were followed for a minimum of 11 years and a maximum of 22 years. $139(74.3 \%)$ have died and $48(25.7 \%)$ are still under clinical follow-up. Patient characteristics are summarized in Table 1. Most of them were elderly men. The main associated clinical conditions were hypertension (63.6\%), smoking (63.1\%), Chronic Obstructive Pulmonary Disease (COPD) (26.2\%) and diabetes (13.4\%) as in Table 1. Among these patients, three (1.63\%) required a second endovascular procedure, due to the elbow branching of the endoprosthesis. Seven patients $(3.7 \%)$ had endotension, with an increase in the diameter of the aneurysm sac greater than $10 \mathrm{~mm}$. One $(0.5 \%)$ required open surgical correction by increasing the diameter of the sac by $24 \mathrm{~mm}$ over 11 years. In this sample, there was a significant correlation between death and complete shrinkage (P-value 0.002). The median rate of aneurysmal sac resorption after EVAR is being followed for a long-term. In the preoperative period, the mean aneurysmal sac diameter was $59.3 \pm 14.3 \mathrm{~mm}$ (median $57 \mathrm{~mm}$ ). 30 days after the procedure, it reduced to $57.6 \pm 14.7 \mathrm{~mm}$ (median $55 \mathrm{~mm}$ ) and continued decreasing during the follow-up. In the first year $(\mathrm{n}=163)$ the mean diameter of the sac was $55.4 \pm 15.4 \mathrm{~mm}$ (median $53.5 \mathrm{~mm}$ ). After 5 years $(n=102)$, the average size of the sac was $49.1 \pm 17.3 \mathrm{~mm}$

Table 1: Patient characteristics.

\begin{tabular}{|c|c|}
\hline Characteristics & N = 187 (\%) or median (SD) \\
\hline Aneurysmal sac diameter & $59.3 \pm 14.3 \mathrm{~mm}$ \\
\hline Male/female & $151(80.7) / 36(19.3)$ \\
\hline Age & $71.7+7.8$ years \\
\hline Hypertension & $119(63.6)$ \\
\hline Smoking & $118(63.1)$ \\
\hline Diabetes & $25(13.4)$ \\
\hline Chronic obstructive pulmonary disease & $49(26.2)$ \\
\hline
\end{tabular}

Table 2: Best fit model for shrinkage prediction and logistic regression coefficients.

\begin{tabular}{|c|c|c|c|}
\hline Parameters & Estimate & Standard error z & P value \\
\hline (Intercept) & 17.64824 & 3.46419 & $3.50 \mathrm{E}-07$ \\
\hline Age & -0.06364 & 0.03499 & 0.0689 \\
\hline Aneurysmal size & -0.28609 & 0.05338 & $8.34 \mathrm{E}-08$ \\
\hline
\end{tabular}


Table 3: Probability of complete shrinkage according to age and aneurysmal size.

\begin{tabular}{|c|c|c|c|}
\hline Size \& Age & 62 years & 72 years & 82 years \\
\hline $45 \mathrm{~mm}$ & $69.60 \%$ & $54.80 \%$ & $39.10 \%$ \\
\hline $55 \mathrm{~mm}$ & $11.60 \%$ & $6.50 \%$ & $3.50 \%$ \\
\hline $65 \mathrm{~mm}$ & $0.70 \%$ & $0.40 \%$ & $0.20 \%$ \\
\hline
\end{tabular}

(median $46 \mathrm{~mm}$ ). After 10 years ( $\mathrm{n}=63$ ), the mean was $42.7 \pm 16.4 \mathrm{~mm}$ (median $36 \mathrm{~mm}$ ). After 15 years $(\mathrm{n}=34)$, the average size of the SAC was $40.4 \pm 16.4 \mathrm{~mm}$ (median $34 \mathrm{~mm}$ ). Finally, after 20 years of followup, $(\mathrm{n}=12)$ the mean size of the sac was $31.7 \pm 8.8 \mathrm{~mm}$ (median 31 $\mathrm{mm}$ ). The univariate analysis identified that only age (P-value $<0.001)$ and aneurysmal size $(\mathrm{P}$-value $<0.001)$ were statistically significant for complete shrinkage. The final best fit model according to AIC to predict complete aneurysmal shrinkage included the combination of age and aneurysmal size before EVAR (Table 2).

\section{Absorption x AAA size}

Among the 75 patients with small aneurysms $(<55 \mathrm{~mm}), 36$ (48.0\%) had a reduction of $10 \mathrm{~mm}$ or more in the initial diameter; 7 patients (9.3\%) had a moderate reduction (between $5 \mathrm{~mm}$ to $9 \mathrm{~mm}$ ) in the diameter of the aneurysm and $32(42.7 \%)$ had no significant reduction or presented an increase in the diameter of the aneurysm. Finally, 28 (37.3\%) had complete shrinkage. Among the 112 patients with large aneurysms ( $\geq 55 \mathrm{~mm}), 34(30.4 \%)$ presented a reduction $\geq 10 \mathrm{~mm} ; 21(18.8 \%)$ had a moderate reduction $(5 \mathrm{~mm}$ to $9 \mathrm{~mm}$ ) and $57(50.9 \%)$ had no significant reduction or had an increase in the diameter of the aneurysm. Only six patients (5.4\%) had complete shrinkage. There was a significant difference (P-value <0.001) for complete shrinkage between patients with small versus large aneurysms.

\section{Absorption $x$ age}

Assessing patients by age, we analyzed them in two groups by the median in the sample in order to have a similar " $n$ " of the groups. Therefore, we considered patients up to 72 years old to be the youngest group and patients aged 73 years or older to be the oldest group. In the group of young patients ( $\mathrm{n}=101$ patients), the average age was $65.3 \pm 5.5$ years (median 67 years) and the diameter of the sac preoperatively was an average of $58.3 \pm 15.1 \mathrm{~mm}$ (median $55 \mathrm{~mm}$ ). In control CT angiography, 30 days after the procedure, the mean size of the sac was $56.1 \pm 15.1 \mathrm{~mm}$ (median $52 \mathrm{~mm}$ ). Among the young patients, $43(42.6 \%)$ presented a decrease of $10 \mathrm{~mm}$ or more in the sac, $14(13.9 \%)$ presented a moderate decrease $(5 \mathrm{~mm}$ to $9 \mathrm{~mm})$ and 44 (43.6) presented little or no resorption of the sac. In this group of young patients, $24(23.8 \%)$ had total absorption. The group of older patients ( $\mathrm{n}=86$ patients) had a mean age of $77.6 \pm 4.1$ years (median 78 years). The average diameter of the sac preoperatively was $60.4 \pm 13.2$ $\mathrm{mm}$ (median $58.5 \mathrm{~mm}$ ). In the tomographic control, 30 days after the endovascular procedure, the patients had an average of $59.3 \pm 14.1$ $\mathrm{mm}$. Among the older patients, $26(30.2 \%)$ presented a decrease of 10 $\mathrm{mm}$ or more in the sac, $14(16.3 \%)$ presented a moderate decrease (5 $\mathrm{mm}$ to $9 \mathrm{~mm}$ ) and $46(53.5 \%)$ presented a small or no resorption of the sac. In this group of older patients, 10 (11.6\%) had total absorption. The statistical difference in sac absorption between the youngest half and the oldest half was significant ( $\mathrm{p}=0.029$ ).

\section{Sac absorption of small aneurysms and younger patients}

When evaluating patients classified as younger ( $\leq 72$ years) and having aneurysms considered small $(<55 \mathrm{~mm})$, there was a group of 55 patients with an average age of $64.9 \pm 5.5$ years (median 67 years). The average diameter of the sac was $48.3 \pm 4.8 \mathrm{~mm}$ (median $49 \mathrm{~mm}$ ). In the tomographic control, the patients had an average of $46.1 \pm 5.1 \mathrm{~mm}$ (median $46 \mathrm{~mm})$. After one year $(\mathrm{n}=49)$, the mean diameter was $43.7 \pm 6.2 \mathrm{~mm}$ (median $=44 \mathrm{~mm})$. After 5 years, $(\mathrm{n}=40)$ the average size of the sac was $39.1 \pm 9.6 \mathrm{~mm}$ (median $36 \mathrm{~mm}$ ). After 10 years $(\mathrm{n}=32)$, the mean was $37.4 \pm 11.5 \mathrm{~mm}$ (median $32.5 \mathrm{~mm}$ ). After 15 years $(n=20)$, the average was $36.3 \pm 11.7 \mathrm{~mm}$ (median 32 $\mathrm{mm})$. After 20 years $(\mathrm{n}=7)$, the average was $30.3 \pm 1.5 \mathrm{~mm}$ (median $30 \mathrm{~mm}$ ) (Figure 2). Among these, 26 (47.3\%) presented a decrease in aneurysmal sac $\geq 10 \mathrm{~mm}, 9(16.4 \%)$ presented a moderate decrease (5 $\mathrm{mm}$ to $9 \mathrm{~mm}$ ) and $20(36.4 \%)$ presented a small or no shrinkage. 22 patients $(40.0 \%)$ presented a complete shrinkage.

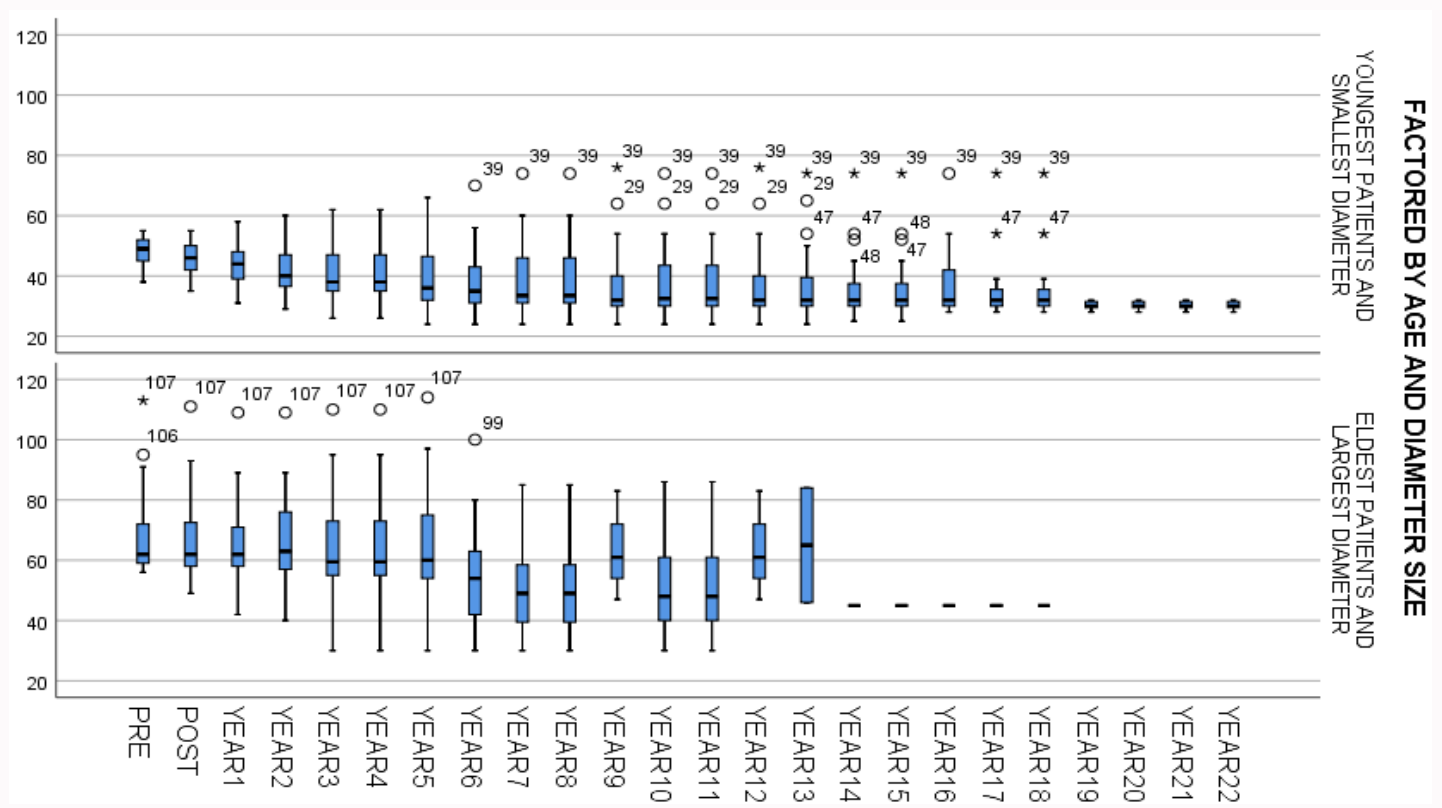

Figure 2: Boxplot of the aneurysmal sizes comparing the follow-up of the younger half of the patients with small aneurysms and the older half of the patients with large aneurysms. 


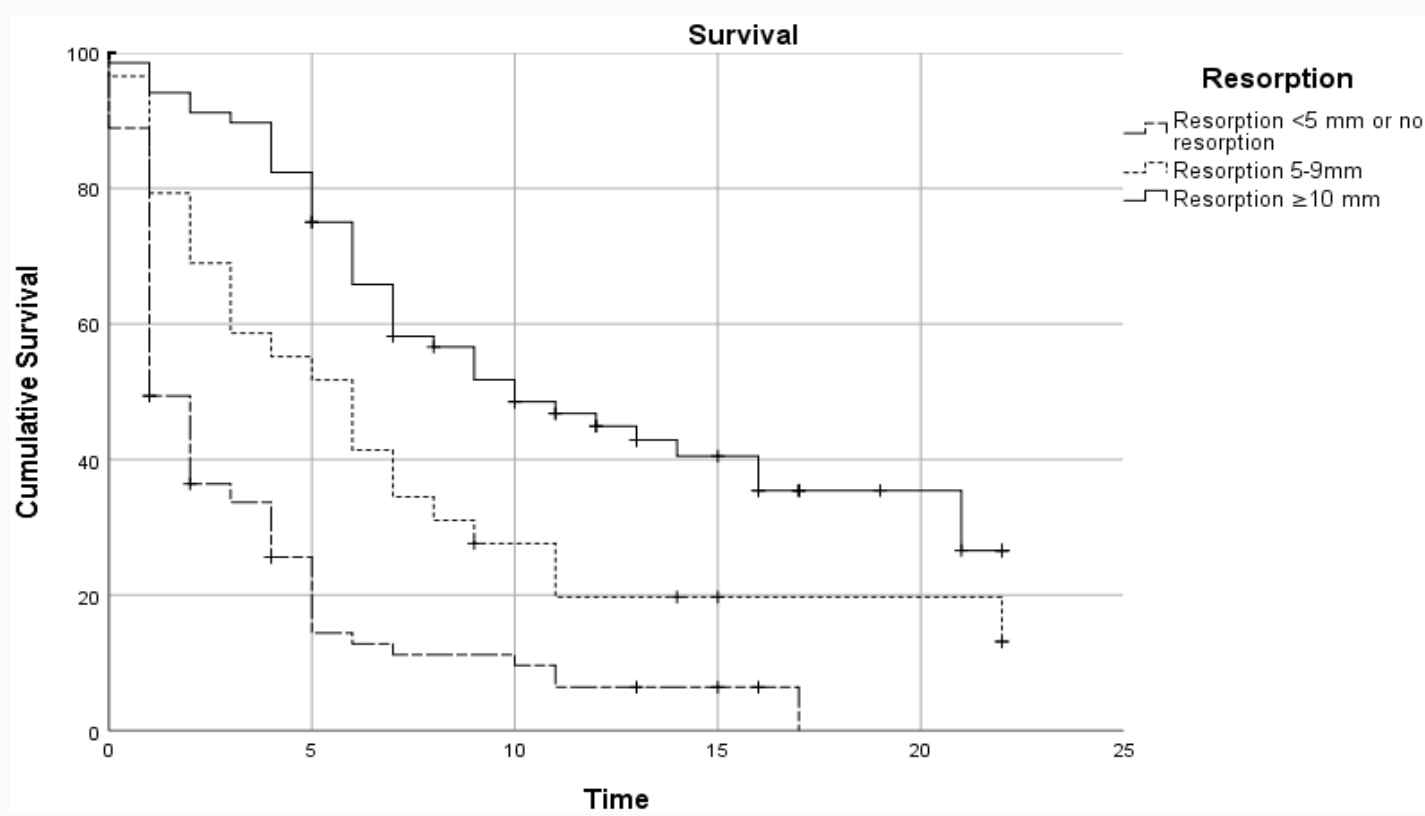

Figure 3: Kaplan-Meier estimator for survival in patients with significative SAC shrinkage (>10 mm), moderate shrinkage (5-9 mm) and no shrinkage or with growth.

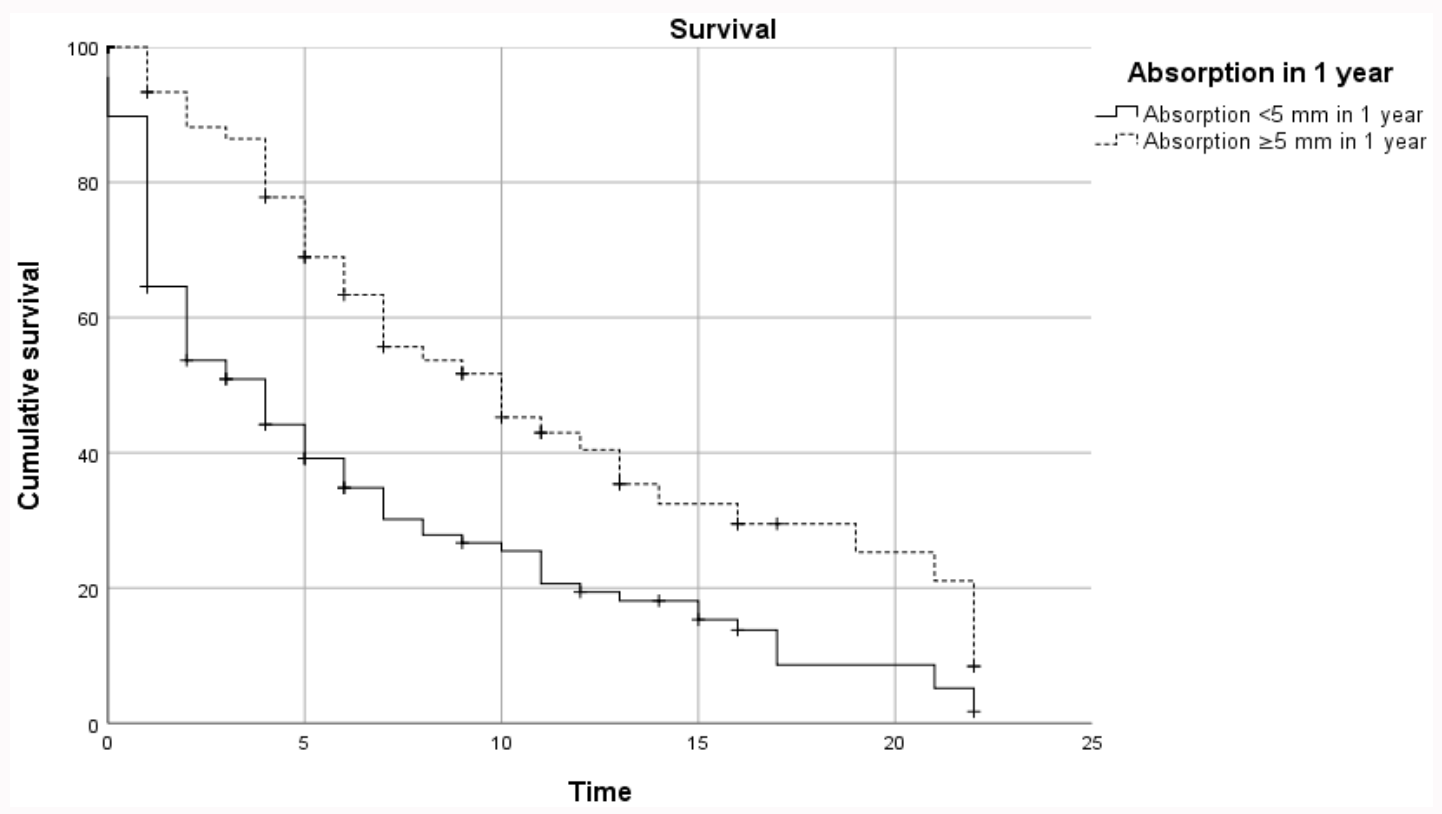

Figure 4: Kaplan-Meier in patients with early absorption ( $\geq 5 \mathrm{~mm}$ in 1 year) and without early absorption after 22 years

\section{Sac absorption of large aneurysms and older patients}

When evaluating patients classified as older ( $\geq 73$ years) and with aneurysms considered large ( $\geq 55 \mathrm{~mm}$ ), there was a group of 52 patients with an average age of $77.9 \pm 4.0$ years (median 78 years). In the tomographic control, the patients had an average of $66.8 \pm 12.7$ $\mathrm{mm}$ (median $62 \mathrm{~mm})$. After one year $(\mathrm{n}=43)$, the mean diameter was $66.2 \pm 12.6 \mathrm{~mm}$ (median $=62 \mathrm{~mm})$. After 5 years $(\mathrm{n}=19)$, the average size of the sac was $63.3 \pm 20.9 \mathrm{~mm}$ (median $60 \mathrm{~mm}$ ). After 10 years $(\mathrm{n}=9)$, the mean was $53.1 \pm 19.5 \mathrm{~mm}$ (median $48 \mathrm{~mm})$. After 15 years, there was only 1 patient with an AAA diameter of $45.0 \mathrm{~mm}$ (Figure 2). Among these, 14 (26.9\%) had a decrease in aneurysmal sac of $\geq$ $10 \mathrm{~mm}, 9(17.3 \%)$ had a moderate decrease $(5 \mathrm{~mm}$ to $9 \mathrm{~mm}$ ) and 29 (55.8\%) had a small or no shrinkage. Two patients (3.8\%) presented a complete shrinkage. There was a significant difference (P-value
$<0.001)$ in the shrinkage between the groups of younger patients with small aneurysms and older patients with large aneurysms. The impact of the size of the aneurysm into the probability of complete shrinkage with EVAR is noteworthy. In Table 3, the probability is estimated of complete shrinkage for patients aged 72 (the median sample) varying \pm 10 years and aneurysmal size $55 \mathrm{~mm}$ (cut-off value for large aneurysms) varying $\pm 10 \mathrm{~mm}$.

\section{Absorption and survival}

Among patients $(\mathrm{n}=89)$ without significant sac absorption $(<5 \mathrm{~mm})$, life expectancy was $3.27 \pm 0.48$ years. In the cumulative proportion over time, the survival of these patients was $87.5 \pm 3.34 \%$ at the end of the first year, $22.5 \pm 4.6 \%$ after five years, $9.0 \pm 3.4 \%$ after ten years and $6.0 \pm 2.8 \%$ after fifteen years. In patients $(n=28)$ 
with a moderate decrease in sac ( $5 \mathrm{~mm}$ to $9 \mathrm{~mm})$, life expectancy was $8.34 \pm 1.62$ years. In the cumulative proportion over time, the survival of these patients was $86.4 \pm 7.3 \%$ after one year; $63.6 \pm 10.3 \%$ after five years; $27.3 \pm 9.5 \%$ after ten years; $22.5 \pm 9.3 \%$ after fifteen years and $12.3 \pm 8.6 \%$ after 20 years. Finally, in patients with a significant decrease in sac $(n=70 ; \geq 10 \mathrm{~mm})$, life expectancy was $12.72 \pm 0.96$ years. The proportion of cumulative survival overtime for these patients was $95.7 \pm 2.5 \%$ after one year; $85.5 \pm 4.2 \%$ after five years $53.9 \pm 6.1 \%$ after ten years; $41.6 \pm 6.3 \%$ after fifteen years and 29.6 $\pm 6.9 \%$ after 20 years (Figure 2). The difference between the three groups was statistically significant $(\mathrm{P}$-value $<0.001)$ (Figure 3 ).

\section{Early sac absorption}

When evaluating the influence of early sac absorption, we found that a shrinkage of $\geq 5 \mathrm{~mm}$ in the first year after the procedure is statistically significant for complete shrinkage, with an Odds Ratio (OR) of 4.72; Confidence Interval (CI) 3.17 to 7.03). Analyzing a sac shrinkage of $\geq 5 \mathrm{~mm}$ in the first month of post operation was not statistically significant for complete shrinkage. Among patients $(n=60)$ without early sac absorption ( $\geq 5 \mathrm{~mm}$ in 1 year), life expectancy was $11.3 \pm 1.3$ years. In the cumulative proportion over time, the survival of these patients was $68.9 \pm 6.1 \%$ after five years, $45.2 \pm 6.9 \%$ after ten years, $32.4 \pm 6.9 \%$ after fifteen years and $25.3 \pm 7.1 \%$ after 20 years.

In patients $(\mathrm{n}=127)$ with no significant early sac absorption $(<5$ $\mathrm{mm}$ in 1 year), life expectancy was $6.3 \pm 0.67$ years. In the cumulative proportion over time, the survival of these patients was $39.2 \pm 4.7 \%$ after five years; $25.5 \pm 4.4 \%$ after ten years; $15.3 \pm 3.8 \%$ after fifteen years and $5.2 \pm 2.8 \%$ after 20 years. The difference between both groups was statistically significant $(\mathrm{P}$-value $<0.001$ ) (Figure 4 ).

\section{Discussion}

Data regarding the long-term follow-up of aortic aneurysms and the relationship between shrinkage and survival is scarce and contradictory. Despite this, most of the published data attests that no aneurysmal shrinkage after EVAR increases the risks of longterm complications such as re-operation, endoleaks and death $[7,8]$. A decrease of $>5 \mathrm{~mm}$ after EVAR is associated with a statistically significant increase in survival $[9,10]$. Our study showed that patients with significant aneurysmal sac absorption $(>10 \mathrm{~mm})$ survived longer than those with less resorption ( $5 \mathrm{~mm}$ to $9 \mathrm{~mm}$ ) and especially in relation to those with a small $(<55 \mathrm{~mm})$ or no absorption. The aneurysmal size was the most relevant risk factor for shrinkage in our cohort. Large aneurysms are well known to be associated with worse outcomes. In a meta-analysis involving 22,104 patients with AAA correction, the aneurysmal sac diameter was identified as an important predictor of survival, both for endovascular and open surgery [11]. Furthermore, age and cardiovascular disease have been considered independent risk factors. EVAR in small aneurysms is associated with a lower mortality rate related to aneurysmal rupture. However, the total number of endovascular procedures increases by about $21.9 \%$ and increases overall costs [12]. In our follow-up, patients with small aneurysms had significantly higher odds of shrinkage (P-value $<0.01)$. This data may influence in the discussion about the cut-off limits for the indication of EVAR in patients with AAA. EVAR efficacy is not exclusively related to the studied risk factors. There may be differences in the proportion of sac absorption depending on the type of endoprosthesis and surgical technique [13]. This study has no such bias because it was intentionally performed with the same type of stent (Talent') and with the same surgical team for all the patients. Besides aneurysm size, the age of patients was also an important risk factor for aneurysmal shrinkage (P-value $<0.001)$. In the younger half, complete shrinkage was about three times more frequent, which is a finding in accordance with other cohorts [14]. The association between younger patients ( $<72$ years) with small aneurysms presented 10.52 times more chances of complete shrinkage than older patients with large aneurysms (P-value $<0.001)$. According to our model, a $6.2 \%$ risk reduction is estimated for complete shrinkage for each year. Early sac shrinkage has been an important predictor for absorption. $A \geq 10 \%$ volume aneurysmal sac reduction in the first six months is a reliable predictor of success $[7,11]$. An aneurysmal sac reduction in the postoperative period is related to its behavior over the years, considering an absorption of $10 \mathrm{~mm}$ within 24 months to be significant $[7,11,15,16]$. In our study, there was a significant higher survival in patients who had an initial absorption of $5 \mathrm{~mm}$ in the first year angio-CT control $(\mathrm{P}$-value $<0.001)$ and in patients with complete shrinkage (P-value $<0.001$ ). There are some limitations in our study. Firstly, we did not use volumetry to evaluate the changes in the sac sizes, which is considered a superior evaluation tool compared with measuring the diameter alone [17]. Secondly, this was a single center retrospective analysis of a prospectively maintained database. Significant differences may exist among ethnic groups in terms of demographic and anatomic characteristics and, therefore, the reproducibility of our findings within other ethnic populations is unclear $[17,18]$. Not all possible risk factors were analyzed. Statin use, renal dysfunction and coronary disease were not tested. Finally, the relatively small sample $(n=187)$ may have limited the statistical power analysis for the possible risk factors studied. For example, smoking is related to less complications after EVAR with a protective effect on the formation of endoleaks, probably due to its pro thrombogenic factor $[19,20]$. However, in our study, although smoking has been a positive prognostic factor for sac shrinkage, no statistical significance was found (P-value 0.61).

Patients with a low probability of reducing sac represent a higher risk of complications and may require more long-term, intensive observation [10,21,22]. Even patients with a significant shrinkage of the sac should not stop their clinical follow-up. In this study, 13 patients (6.9\%) had an aneurysm growth, five in the first year after EVAR, one after three years, two after five years, one after six years, and one after seven years, two after nine years and one after ten years of follow-up. We believe that abdominal (no contrast) tomography is sufficient for the proper follow-up after EVAR in patients with continuous aneurysmal sac reduction [3,23-25]. Our study represents a long-term follow-up (22 years) of patients with EVAR. It reinforces the concept that aneurysmal sac shrinkage may be considered a surrogate indicator of the success of EVAR, indicating the exclusion of the aneurysm from arterial pressure and its relationship with improved, long-term survival.

\section{Conclusion}

Aneurysmal sac shrinkage is a successful marker for the treatment of patients with AAA submitted to EVAR. Complete shrinkage and age are significantly associated with longer survival. In this long-term cohort study, the most important risk factor associated with complete aneurysmal shrinkage after EVAR is the preoperative aneurysmal diameter.

\section{References}

1. Earnshaw JJ, Lees T. Update on screening for abdominal aortic aneurysm. Eur J Vasc Endovasc Surg. 2017;54(1):1-2.

2. Sylvestre R, Coscas R, Javerliat I, Goeau-Brissonniere O, Coggia M. 
Eligibility rates for ambulatory EVAR. Ann Vasc Surg. 2019;58:7-15.

3. Patel R, Sweeting MJ, Powell JT, Greenhalgh RM; EVAR trial investigators Endovascular $v s$. open repair of abdominal aortic aneurysm in 15-years follow-up of the UK endovascular aneurysm repair trial 1 (EVAR trial 1): A randomised controlled trial. Lancet. 2016;388(10058):2366-74.

4. Zarins CK, Bloch DA, Crabtree T, Matsumoto AH, White RA, Fogarty TJ. Aneurysm enlargement following endovascular aneurysm repair: AneuRx clinical trial. J Vasc Surg. 2004;39(1):109-17.

5. Chikazawa G, Hiraoka A, Totsugawa T, Tamura K, Ishida A, Sakaguchi $\mathrm{T}$, et al. Influencing factors for abdominal aortic aneurysm sac shrinkage and enlargement after EVAR: Clinical reviews before introduction of preoperative coil embolization. Ann Vasc Dis. 2014;7(3):280-5.

6. Espinosa G, di Luccio G, Alves MR, Gutfilen B, Raggio R, Saad P, et al Prospective cohort 20 years after endovascular treatment for abdominal aortic aneurysm. J Vasc Surg. 2018;67(4):1102-9.

7. Bastos Gonçalves F, Baderkhan H, VerhagenHJ, Wanhainen A, Björck M, Stolker RJ, et al. Early sac shrinkage predicts a low risk of late complications after endovascular aortic aneurysm repair. Br J Surg. 2014;101(7):802-10.

8. Torsello G, Scheinert D, Brunkwall JS, Chiesa R, Coppi G, Pratesi C. Safety and effectiveness of the INCRAFT AAA Stent Graft for endovascular repair of abdominal aortic aneurysms. J Vasc Surg. 2015;61(1):1-8.

9. Khashram M, Hider PN, Williman JA, Jones GT, Roake JA. Does the diameter of abdominal aortic aneurysm influence late survival following abdominal aortic aneurysm repair? A systematic review and meta-analysis. Vascular. 2016;24(6):658-67.

10. O'Donnell TFX, Deery SE, Boitano LT, Siracuse JJ, Schermerhorn ML, Scali ST, et al. Aneurysm sac failure to regress after endovascular aneurysm repair is associated with lower long-term survival. J Vasc Surg. 2019;69(2):414-22

11. Lalys F, Daoudal A, Gindre J, Göksu C, Lucas A, Kaladji A. Influencing factors of sac shrinkage after endovascular aneurysm repair. J Vasc Surg. 2017;65(6):1830-8.

12. Tomee SM, Bastiaannet E, Schermerhorn ML, Golledge J, Hamming JF, Lindeman $\mathrm{JH}$. The consequences of real life practice of early abdominal aortic aneurysm repair: A cost-benefit analysis. Eur J Vasc Endovasc Surg. 2017;54(1):28-33.

13. Fujimura N, Obara H, Matsubara K, Sekimoto Y, Harada H, Masaroni I, et al. Comparison of Early Sac Shrinkage with Third-Generation Stent Grafts for Endovascular Aneurysm Repair. J VascInterv Radiol. 2016;27(10):1604-12.e2.

14. Soler RJ, Bartoli MA, Mancini J, Lerussi G, Thevenin B, Sarlon-Bartoli G et al. Aneurysm sac shrinkage after endovascular repair: Predictive factors and long-term follow-up. Ann Vasc Surg. 2015;29(4):770-9.
15. Stather PW, Sidloff D, Dattani N, Choke E, Brown MJ, Sayers RD. Systematic review and meta-analysis of the early and late outcomes of open and endovascular repair of abdominal aortic aneurysm. Br J Surg. 2013;100(7):863-72.

16. Lim S, Halandras PM, Park T, Lee Y, Crisostomo P, Hershberger R, et al. Outcomes of endovascular abdominal aortic aneurysm repair in high-risk patients. J Vasc Surg. 2015;61(4):862-8.

17. Fujimura N, Matsubara K, Takahara M, Harada H, Asami A, Shibutani $\mathrm{S}$, et al. Early sac shrinkage is a good surrogate marker of durable success after endovascular aneurysm repair in Japanese patients. J Vasc Surg. 2018;67(5):1410-8.

18. Tsuyuki Y, Matsushita S, Dohi S, Yamamoto T, Tambara K, Inaba H, et al. Factors for sac size change of abdominal aortic aneurysm after endovascular repair. Ann Thorac Cardiovasc Surg. 2014;20(6):1016-20.

19. Laine MT, Laukontaus SJ, Sund R, Aho PS, Kantonen I, Albäck A, et al. A population-based study of abdominal aortic aneurysm treatment in Finland 2000 to 2014. Circulation. 2017;136(18):1726-34

20. Lange C, Leurs LJ, Buth J, Myhre HO; EUROSTAR collaborators. Endovascular repair of abdominal aortic aneurysm in octogenarians: An analysis based on EUROSTAR data. J Vasc Surg. 2005;42(4):624-30.

21. Bisdas T, Weiss K, Eisenack M, Austermann M, Torsello G, Donas KP. Durability of the endurant stent graft in patients undergoing endovascular abdominal aortic aneurysm repair. J Vasc Surg. 2014;60(5):1125-31.

22. Houbballah R, Majewski M, Becquemin JP. Significant sac retraction after endovascular aneurysm repair is a robust indicator of durable treatment success. J Vasc Surg. 2010;52(4):878-83.

23. Sweeting MJ, Patel R, Powell JT, Greenhalgh RM; EVAR Trial Investigators. Endovascular repair of abdominal aortic aneurysm in patients physically ineligible for open repair: very long-term follow-up in the evar-2 randomized controlled trial. Ann Surg. 2017;266(5):713-9.

24. Stather PW, Sidloff D, Dattani N, Choke E, Bown MJ, Sayers RD. Systematic review and meta-analysis of the early and late outcomes of open and endovascular repair of abdominal aortic aneurysm. Br J Surg. 2013;100(7):863-72.

25. Langenberg JC, Roijers J, Ho GH, Veen J Eelco, Vos D, Buimer T, et al. Post-EVAR aneurysm sac shrinkage is prognostically favorable, but does not justify withholding follow-up. J Cardiovasc Surg (Torino). 2020;61(3):317-22 